\title{
APLICACIÓN DE LA METODOLOGÍA CORINE LAND COVER EN LA DETERMINACIÓN DE LOS CAMBIOS DE COBERTURA EN EL PAROUE NATURAL LOS FLAMENCOS
}

\author{
APPLICATION OF THE CORINE LAND COVER METHODOLOGY \\ TO DETERMINE THE ENVIRON CHANGES IN THE NATURAL PARK LOS FLAMENCOS
}

\begin{abstract}
Luisa Patricia Corredor Gil
Ing. Forestal, Especialista en Geomática, Monitora de Coberturas de la Tierra del Sistema de Parques Nacionales Naturales, Unidad Administrativa Especial del Sistema de Parques Nacionales Naturales de Colombia, Bogotá.

luisacorredor@gmail.com
\end{abstract}

Elsa Adriana Cárdenas Quiroga

Geóloga, Msc, Profesora Asistente, Facultad de Ingeniería, Líder Grupo Geomática Aplicada, Universidad Militar Nueva Granada, Bogotá, Colombia

elsa.cardenas@unimilitar.edu.co

Julio César Ordóñez López

Ingeniero en Multimedia, Joven Investigador Grupo Geomática Aplicada,

Universidad Militar Nueva Granada, Bogotá, Colombia

julioc.ordonezl@gmail.com

Fecha de recepción: 14 de junio de 2011

Fecha de aprobación: 19 de diciembre de 2011

\section{RESUMEN}

La funcionalidad de los sistemas naturales depende de un delicado equilibrio resultante de la correcta interacción entre sus componentes biológicos y no biológicos. En el caso particular del Santuario de Flora y Fauna Los Flamencos, las actividades humanas han interrumpido dicho equilibrio, generando cambios en su cobertura natural. Siendo tan significativos dichos cambios y tan complejas sus consecuencias, que se hace necesario adelantar estudios como el propuesto en el presente trabajo, tendientes a evaluar las transformaciones experimentadas por la cobertura natural en el Santuario de Flora y Fauna Los Flamencos, empleando herramientas como la teledetección y los Sistemas de Información Geográfica. El desarrollo del trabajo se basó en un análisis multitemporal de imágenes satelitales de los años 1987 y 2007, siguiendo los lineamientos impuestos por la metodología CORINE Land Cover, que fue desarrollada por primera vez en Europa e implementada luego en Colombia, gracias a la ejecución de varios proyectos de estudios de cobertura vegetal a nivel nacional. Adicionalmente, para este trabajo se efectúo la interpretación visual asistida por computador de imágenes landsat, utilizando medios informáticos especializados. Los resultados finales fueron analizados estadísticamente y plasmados en el mapa de cambios en la cobertura entre los años mencionados.

Palabras clave: coberturas de tierra, sistemas de información geográfica, usos de la tierra, ordenamiento territorial, cartografía. 


\begin{abstract}
The functionality of the natural systems depends on the resulting balance from the proper interaction between its biological and non-biological components. In the particular case of the Los Flamencos flora and fauna sanctuary, the human activities have interrupted this balance and have generated changes in its natural environs. As these changes are so significant and its consequences are very complex, the development of studies such as the one proposed in this paper are necessary, to evaluate the transformations suffered by the Sanctuary's natural, using GIS and remote sensing tools. This work is based on a multitemporal analysis of satellite images carried out between 1987 and 2007, following the CORINE Land Cover methodology, which was first developed in Europe and later implemented in Colombia through some projects on environ studies at national scale. Furthermore, for this project a computer-aided visual interpretation of landsat images was carried out, using special software. The final results were statistically analyzed and shown on a map of the changes taking place in natural environs changes during the years mentioned above.
\end{abstract}

Keywords: land cover, geographic information system, land uses, territorial planification, cartography.

\title{
INTRODUCCIÓN
}

Los aportes de la teledetección a los estudios ambientales radican en su capacidad para seguir procesos dinámicos [2]. En el mundo, la teledetección se ha empleado para identificar cambios en la cobertura y uso de la tierra, además del estudio de otro tipo de eventos, algunos esporádicos como erupciones volcánicas o incendios, y otros continuos como inundaciones, además de aquellos que tienen su origen en las actividades antrópicas.

En la actualidad, el desarrollo de estudios multitemporales aplicados a la detección de cambios en las coberturas de la tierra, ha cobrado una especial importancia en el ámbito de la ordenación del territorio y en el caso especial de las áreas protegidas, en la formulación de políticas tendientes a la conservación y protección de los recursos naturales.

En Colombia, este tipo de estudios se han venido desarrollando por entidades como el IGAC, desde finales de la década de los 80, inicialmente aplicados a la detección de cambios geomorfológicos y en los últimos años, a la determinación de cambios en las coberturas de la tierra.

Dentro de los proyectos desarrollados asociados con esta temática se pueden relacionar el trabajo titulado "Estudio multitemporal de los manglares de la franja costera del departamento del Atlántico", realizado con la participación de la Corporación Autónoma Regional del Atlántico (CRA), en 1998 y el proyecto desarrollado por CORPOICA en asocio con el IGAC, titulado 
"Análisis multitemporal de la biosfera con el uso de sensores remotos y sistemas de información geográfica en la región de La Mojana" en 1996.

La metodología CORINE Land Cover viene siendo utilizada en Colombia desde el año 2004, cuando se inició el proyecto de su adaptación a las condiciones del país y donde participaron el IGAC, el IDEAM y CORMAGDALENA sobre el área de jurisdicción de esta última. A finales de 2010 estas mismas entidades en convenio con La unidad de parques y los institutos de investigación, han terminado el mapa de coberturas de la tierra para los años 2000-2002, que está por publicarse, usando esta misma metodología. Así mismo, se han adelantado ejercicios de actualización a los años 2005-2007 en algunos sectores del territorio nacional, pero no se han publicado ejercicios de análisis multitemporal propiamente dichos.

Debido a que en Colombia, aún son pocos los estudios que utilizan imágenes satelitales para identificar cambios en la cobertura vegetal, se pensó en desarrollar un proyecto de carácter académico, cuyo propósito principal fuera el estudio multitemporal de coberturas en el Santuario de Flora y Fauna "Los Flamencos" a escala 1:100.000, para determinar los cambios experimentados por las coberturas en el período comprendido entre 1987 y 2007, empleando la metodología CORINE Land Cover, con miras a obtener información cartográfica relevante que pudiera servir como base para proponer o redefinir políticas de protección de recursos en el área.

\section{MATERIALES Y MÉTODOS}

\subsection{CORINE LAND COVER}

La metodología que se siguió para el desarrollo de este proyecto, se basa en los lineamientos propuestos por el proyecto CORINE (por sus siglas en inglés programa de coordinación de información del medio ambiente), específicamente en el proyecto enfocado a la cobertura de la tierra CORINE Land Cover, desarrollado por primera vez en Europa, en la década de los 90, con el fin de estandarizar las nomenclaturas de las coberturas terrestres para todos los países de la Región, que permitiera hacer una comparación entre los usos de los suelos de los mismos y tomar decisiones de carácter global y regional.

Para tal fin, el proyecto CORINE (Dentro de la Comisión Europea) plantea tres objetivos principales [3]:

- Compilar información sobre el estado del ambiente, teniendo en cuenta ciertos temas que tienen prioridad para todos los Estados que conforman la Comisión.

- Coordinar la compilación de datos y la organización de la información entre los Estados de la Comisión o en el ámbito internacional.

- $\quad$ Asegurar que la información sea consistente y que los datos obtenidos sean compatibles.

De esta manera, se puede definir el proyecto CORINE Land Cover como una metodología específica elaborada para realizar el inventario de la cobertura de la tierra [4]. 
La metodología CORINE Land Cover fue concebida inicialmente, para ser un procedimiento que se basara principalmente en técnicas de procesamiento de imágenes, aunque para esa época el equipo que se necesitaba y la relación costo-beneficio imposibilitaban el desarrollo completo de esta idea [1]. Sin embargo, se utilizaron estas técnicas en una primera etapa de todo el proceso, con el fin de mejorar la calidad de las imágenes y permitir una mejor fotointerpretación [1]. En resumen, para la metodología es importante complementar el trabajo hecho en el computador con el trabajo del intérprete.

El desarrollo actual de la metodología se lleva a cabo teniendo en cuenta como base, imágenes satelitales a escala 1:100.000 [3] y [4], que permiten tener una visión amplia y detallada del terreno por estudiar [3]. Existen varias razones para la determinación de esta escala:

- La información que se obtiene de escalas menores (1:250.000 ó 1:500.000), no es muy detallada.

- $\quad$ Es compatible con proyectos que usan una escala más pequeña (ejemplo: se puede generalizar a una escala de 1:1.000.000).

- $\quad$ Permite la actualización de los mapas de manera sencilla.

- $\quad$ Se ajusta a las restricciones de presupuesto y a los límites de tiempo que se exige dentro de la zona por estudiar.

La escala establecida también permite definir una unidad de mapeo para realizar el inventario. La unidad escogida es de 25 hectáreas, puesto que a la escala manejada (1:100.000) esta unidad puede ser representada por un cuadrado de $5 \times 5 \mathrm{~mm}$ o un círculo de radio $2.8 \mathrm{~mm}$ [3]. Sin embargo, para poder utilizar esta unidad de mapeo, se debe tener en cuenta algunos requerimientos:

- $\quad$ El mapa impreso debe ser legible.

- $\quad$ Debe proveer una representación de las características esenciales del terreno.

- $\quad$ Debe haber una compensación entre costos de operación y disposición de la información requerida de la cobertura terrestre.

\subsection{IMÁGENES SATELITALES}

Para realizar análisis de percepción remota, el intérprete se puede basar en varias fuentes de información como fotografías aéreas, imágenes de radar o imágenes satelitales de una zona específica. En el caso de este proyecto, se utilizaron imágenes satelitales LANDSAT para los años 1987 y 2007.

La resolución que proveen las imágenes satelitales, puede ser Radiométrica o Geométrica. La primera se refiere principalmente a la escala de grises que puede manejar el sensor del satélite; por lo general, se maneja en unidades de 8 bits (0 - 255), 11 bits (0 - 2047), 12 bits (0 - 4095) o 16 bits $(0-65.535)$. La resolución geométrica describe la capacidad del sensor de plasmar una porción de tierra en tan solo un píxel, lo cual varía para cada satélite, por ejemplo para el caso de LANDSAT, puede plasmar 30 metros de terreno en un píxel. Hay casos en los cuales los 
sensores permiten una mayor resolución, llegan a plasmar menos de 1 centímetro de terreno en un píxel y permiten la visualización de video en vivo a través del sensor.

\subsection{METODOLOGÍA}

Como en cualquier estudio, es preciso seguir una metodología que abarque todos los pasos necesarios para llegar al resultado final. La fotointerpretación no es una excepción y es por eso que se plantea una metodología para seguir (Figura 1), teniendo en cuenta la adquisición de las imágenes satelitales, y el análisis visual asistido por computador.

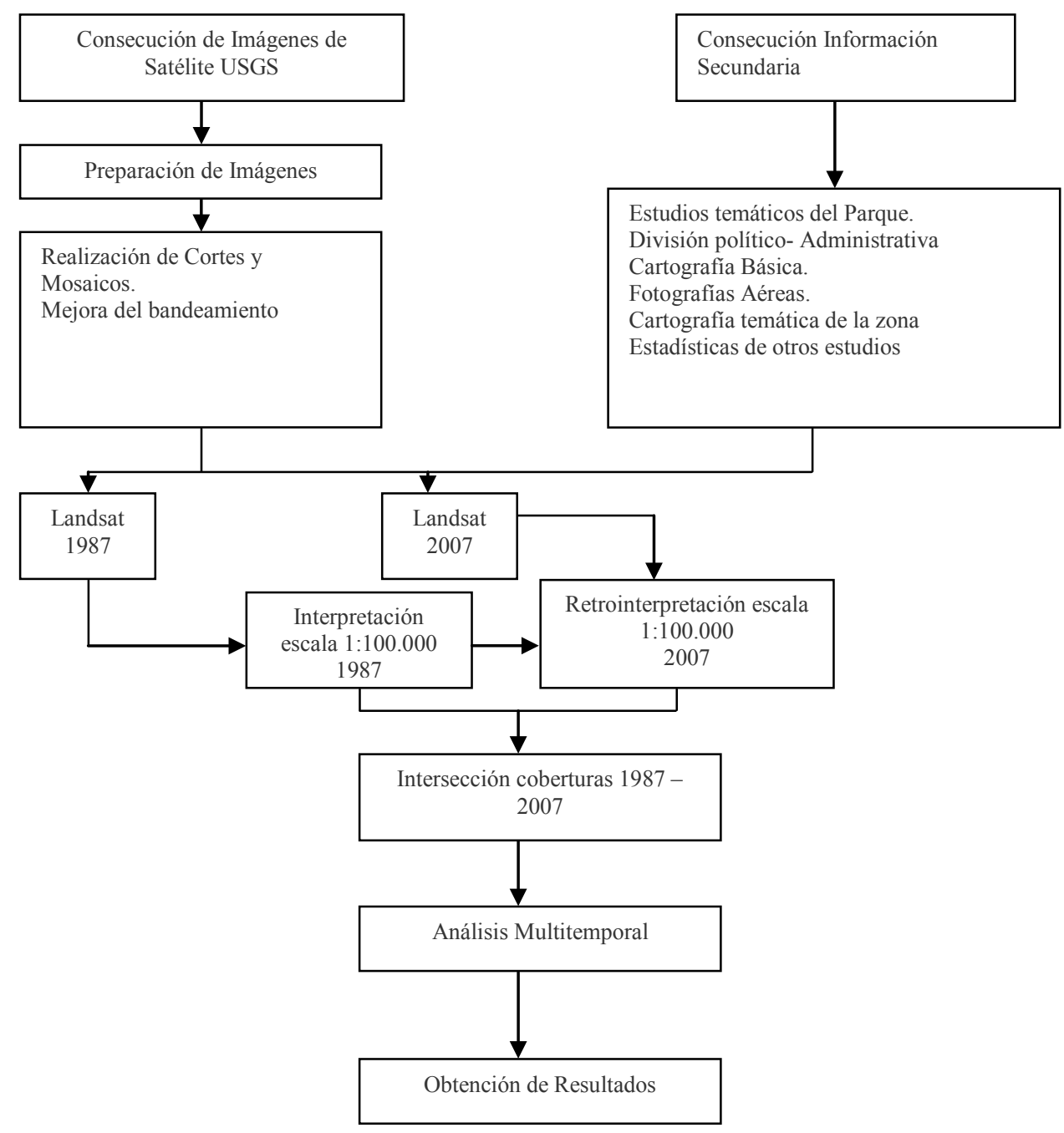

Figura 1. Diagrama de flujo de la metodología 
La obtención de las imágenes satelitales es el primer paso por seguir, pues proveen una perspectiva amplia del terreno a ser estudiado y además, para este trabajo en específico, cumplen los requerimientos de escala de la metodología CORINE Land Cover (1:100.000). Se debe tener en cuenta que antes de hacer los análisis correspondientes, es necesario realizar procesamientos sobre las imágenes para aumentar la veracidad de los datos que se obtengan después, debe efectuarse mejoras de contraste, ecualización de histogramas, reducción de ruido y mejoras del bandeamiento.

Un aspecto importante para tener en cuenta, es que este tipo de trabajos requiere de un control en campo con el fin de corroborar los datos obtenidos mediante el análisis de las imágenes satelitales.

Para el caso del Santuario de Flora y Fauna Los Flamencos, se dificultó la movilidad de los participantes del proyecto hacia el sitio del estudio, por lo cual se evaluó la posibilidad de utilizar fotografías aéreas del mismo terreno para una siguiente etapa del proyecto, con el ánimo de verificar la variación de las coberturas del parque natural dentro del período especificado inicialmente (1987 y 2007).

Luego de definir las fuentes de información (imágenes satelitales y fotografías aéreas) y haberlas procesado previamente para facilitar su lectura, se debe seguir los lineamientos de la metodología CORINE Land Cover para catalogar las coberturas y generar de mapas de la misma. En este paso, se debe tener en cuenta dos procedimientos: la Interpretación que se hace para generar una nueva base de datos de coberturas, teniendo en cuenta la información extraída de la imagen más temprana (1987), y la Retrointerpretación en donde se actualiza la base de datos y se modifican todos los polígonos de coberturas generados.

Finalmente, se hace una intersección de coberturas, con lo cual se establecen los cambios que se han dado durante el período especificado (1987 - 2007). Esto se hace con el objetivo de encontrar cuales elementos han tenido un mayor cambio, bien por la ganancia o pérdida de la cobertura durante el tiempo, y generar un mapa que indique este cambio.

\subsubsection{Localización geográfica y características del área de estudio}

El parque natural Santuario de flora y fauna Los Flamencos, se encuentra ubicado en el departamento de la Guajira, Colombia, entre en las coordenadas geográficas $11^{\circ} 24^{\prime} \mathrm{N}$ y $73^{\circ} 7^{\prime}$ W y cuenta con un área superficial de unos $768 \mathrm{Km}^{2}$. Su temperatura varía entre los $25^{\circ}$ y $30^{\circ} \mathrm{C}$. El Santuario se caracteriza por su riqueza en diversas especies autóctonas y migratorias, y por sus cuatro ciénagas que cubren una extensión aproximada de 7.000 Hectáreas, las cuales en épocas de lluvia se comunican con el mar. 
Dentro de las principales especies vegetales presentes en el área, están los mangles, el bosque seco, el bosque ripario y en algunas zonas, predomina el bosque xerofítico. Algunas de las especies más representativas se mencionan a continuación [7]:

- $\quad$ Cactus cardón (Stenocarus griscus).

- $\quad$ Cactus gamacho (Pereskia colombiana).

- $\quad$ Dividivi (Caesalpinia coriaria).

- Mangle.

- Mangle negro (Avicennia germinans).

- Mangle blanco (Laguncularia racemosa).

- Mangle rojo (Rhizophora brevistyla).

- Mangle zaragoza (Conocarpus erectus).

- Manzanillo venenoso (Hippomane mancinella).

- Olivo (Capparis odoratissima).

- $\quad$ Platanito (Batis maritima).

- $\quad$ Pringamosa (Cnidosculus urena).

- $\quad$ Tripita (Sesuvium portulacastrum).

- $\quad$ Trupillo (Prosopis juliflora).

- Uvito (Cordia dentata).

Geológicamente, el sector de Los Flamencos presenta suelos arcillosos y limolitas grises de origen marino de edad Terciaria, además de suelos transportados de origen aluvial.

\subsubsection{Características del sensor}

Las imágenes Landsat ETM que se utilizaron en el procedimiento cuentan con las siguientes características:

$\begin{array}{ll}\text { Resolución Espacial: } & 30 \text { metros } \\ \text { Resolución Temporal: } & 16 \text { días } \\ \text { Resolución Espectral: } & 8 \text { bandas (3 del visible, Infrarrojo cercano, medio y lejano, una } \\ & \begin{array}{l}\text { termal y una pancromátrica a } 15 \text { metros) } \\ 185 \mathrm{Km}^{2}\end{array}\end{array}$

\subsubsection{Preparación de imágenes}

Las imágenes utilizadas fueron Landsat ETM descargadas gratuitamente del servicio geológico de los Estados Unidos USGS. De este sitio, las imágenes vienen almacenadas banda a banda en sistema de referencia WGS 84 con un nivel de procesamiento básico denominado L1 que incluye una corrección geométrica preliminar. Dado que la zona de estudio es plana, estas características fueron suficientes para realizar el análisis. Para el caso de la imagen del año 2007 que presenta bandeamiento, se ubicó una imagen de fecha cercana de manera que cubriera los “gaps" o pixeles sin información.

\subsubsection{Interpretación}

La metodología de interpretación visual no tiene en cuenta los niveles digitales de la imagen de manera intrínseca, por lo cual el color es sólo una de las variables utilizadas al momento de 
interpretar entre otras, como la textura, la forma, la asociación, el tamaño y el contexto. La combinación utilizada para la interpretación de las imágenes Landsat fue RGB453.

En relación con la calidad de las interpretaciones, ésta se puede asegurar por los siguientes criterios: 1) El intérprete visita el área de estudio previamente a la interpretación para patronar (relacionar el comportamiento de la imagen con la realidad en campo), los diferentes tipos de coberturas. 2) La verificación de la interpretación para la primera época, se realiza utilizando como apoyo un sensor de mayor resolución, en este caso, las fotografías aéreas. Para el segundo período, se hace una visita de campo donde se verifica la exactitud temática de la interpretación, haciendo énfasis en las coberturas de mayor dificultad o duda. En el estudio, se verificaron las siguientes coberturas (Tabla 1):

Tabla 1. Coberturas verificadas

\begin{tabular}{|l|c|c|}
\hline \multicolumn{1}{|c|}{ Cobertura } & Verificacion & $\begin{array}{c}\text { No. Polígonos } \\
\text { verificados }\end{array}$ \\
\hline 3221 Arbustal Denso & Correcto & 4 \\
\hline 233 Pastos Enmalezados o Enrastrojados & Correcto & 3 \\
\hline 111 Tejido urbano continuo & Correcto & 1 \\
\hline 233 Pastos Enmalezados o Enrastrojados & Correcto & 3 \\
\hline 111 Tejido urbano continuo & Correcto & 2 \\
\hline 421 Pantanos costeros & Incorrecto & 2 \\
\hline 313 Bosque de galería o ripario & Correcto & 2 \\
\hline
\end{tabular}

De 17 polígonos verificados, se presentaron 15 correctos y 2 incorrectos lo cual permite calcular una exactitud temática de la interpretación de 88,23\%.

\section{RESULTADOS Y ANÁLISIS}

Se obtuvo los siguientes resultados con el análisis multitemporal teniendo en cuenta la metodología CORINE Land Cover. Primero se presentan las estadísticas individuales para cada época, luego unas estadísticas de cambio de manera general y enseguida, unas estadísticas de cambio que abarcan cada cobertura, indicando el tipo de cambio que sufrió. En la Tabla 2, se presenta el inventario de las coberturas naturales para la imagen del año 1987:

Tabla 2. Estadísticas de coberturas de 1987

\begin{tabular}{|l|l|r|}
\hline \multicolumn{1}{|c|}{ Código } & \multicolumn{1}{|c|}{ Cobertura } & \multicolumn{1}{c|}{$\begin{array}{c}\text { Área acumulada } \\
\text { (Has) }\end{array}$} \\
\hline 3222 & Arbustal Abierto & 302,92 \\
\hline 3221 & Arbustal Denso & 1419,75 \\
\hline 314 & Bosque de galería o ripario & 74,29 \\
\hline
\end{tabular}




\begin{tabular}{|l|l|r|}
\hline \multicolumn{1}{|c|}{ Código } & \multicolumn{1}{|c|}{ Cobertura } & $\begin{array}{c}\text { Área acumulada } \\
\text { (Has) }\end{array}$ \\
\hline 31112 & Bosque de Mangle & 69,76 \\
\hline 521 & Lagunas Costeras & 2420,72 \\
\hline 244 & Mosaico de pastos con espacios naturales & 742,70 \\
\hline 421 & Pantanos costeros & 672,95 \\
\hline 233 & Pastos Enmalezados o Enrastrojados & 407,87 \\
\hline 231 & Pastos Limpios & 44,73 \\
\hline 331 & Playas, Arenales y Dunas & 205,02 \\
\hline 111 & Tejido urbano continuo & 11,54 \\
\hline 323 & Vegetación secundaria o en transición & 941,62 \\
\hline 411 & Zonas Pantanosas & 5,56 \\
\hline & Total general & $\mathbf{7 3 1 9 , 4 2}$ \\
\hline
\end{tabular}

Así mismo, se presenta una imagen que refleja el inventario de coberturas naturales para el mismo año (Figura 2):

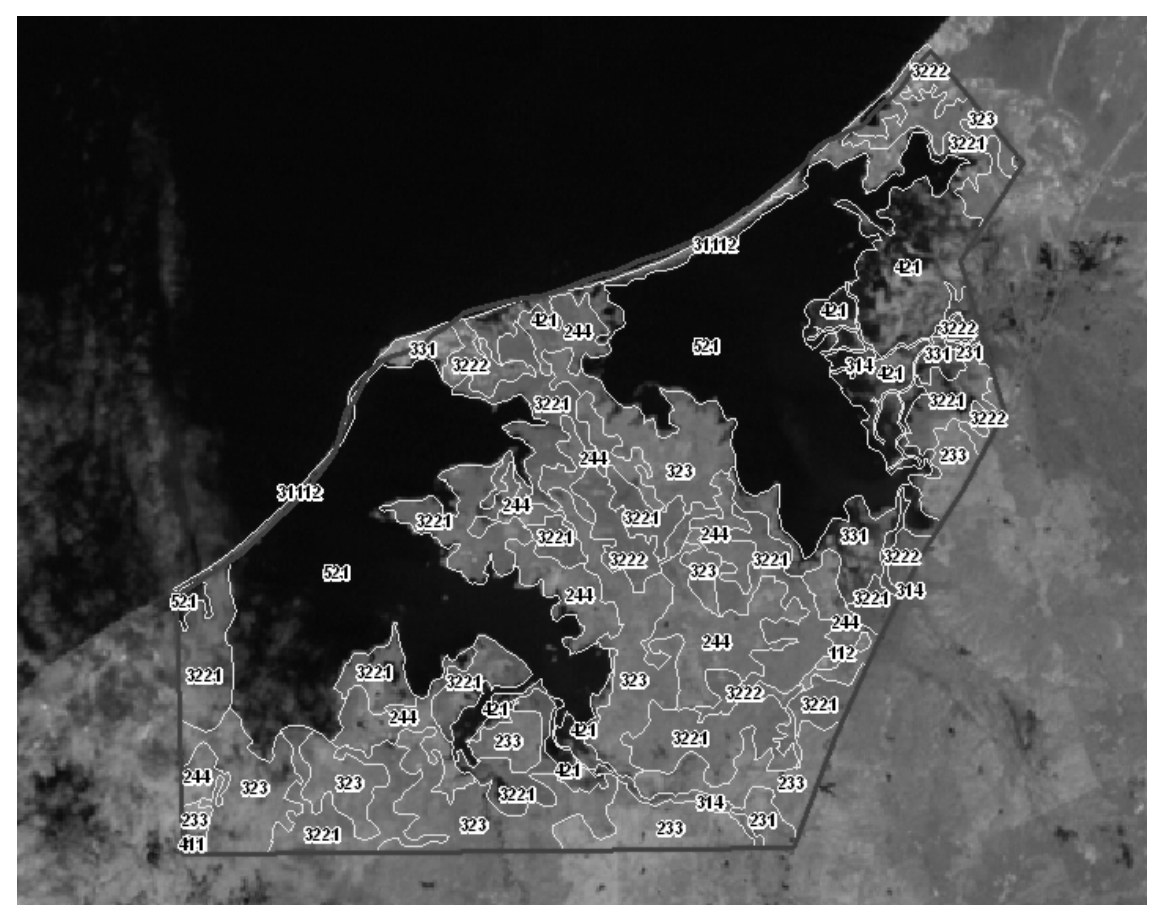

Figura 2. Interpretación de coberturas de 1987

Se realizó el mismo ejercicio para el año 2007. A continuación, se presenta la información obtenida en cuanto a coberturas naturales (Tabla 3 y Figura 3): 
Tabla 3. Estadísticas de coberturas de 2007

\begin{tabular}{|l|l|r|}
\hline \multicolumn{1}{|c|}{ Código Cobertura } & \multicolumn{1}{|c|}{$\begin{array}{c}\text { Área acumulada } \\
\text { (Has) }\end{array}$} \\
\hline 3222 & Arbustal Abierto & 882,94 \\
\hline 3221 & Arbustal Denso & 1926,13 \\
\hline 314 & Bosque de galería y ripario & 74,29 \\
\hline 31112 & Bosque de Mangle & 69,76 \\
\hline 521 & Lagunas Costeras & 2383,28 \\
\hline 244 & Mosaico de pastos con espacios naturales & 198,16 \\
\hline 421 & Pantanos costeros & 201,61 \\
\hline 233 & Pastos enmalezados o enrastrojados & 74,05 \\
\hline 231 & Pastos Limpios & 120,03 \\
\hline 331 & Playas, Arenales y Dunas & 879,28 \\
\hline 111 & Tejido urbano continuo & 12,25 \\
\hline 323 & Vegetación secundaria o en transición & 492,09 \\
\hline 411 & Zonas Pantanosas & 5,56 \\
\hline & Total general & $\mathbf{7 3 1 9 , 4 2}$ \\
\hline
\end{tabular}

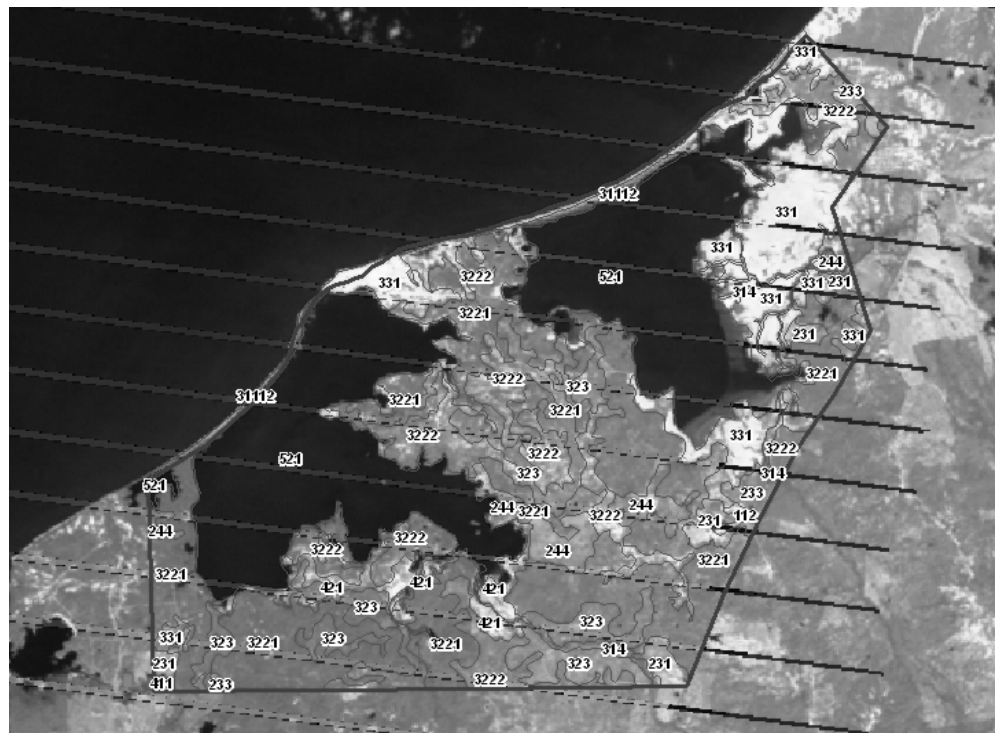

Figura 3. Interpretación de coberturas de 2007.

En todo análisis es necesario determinar el área que ganó o perdió cada cobertura y establecer los cambios que sufrieron. La información se presenta a continuación (Tabla 4 y Tabla 5): 
Tabla 4. Estadísticas de ganancia y pérdida en general

\begin{tabular}{|c|c|c|c|c|}
\hline Código & Coberturas & Área 1987 & Área 2007 & $\begin{array}{l}\text { Ganancia/ } \\
\text { Pérdida }\end{array}$ \\
\hline 3222 & Arbustal Abierto & 302,92 & 882,94 & 580,02 \\
\hline 3221 & Arbustal Denso & $1.419,75$ & $1.926,13$ & 506,38 \\
\hline 314 & Bosque de galería o ripario & 74,29 & 74,29 & 0 \\
\hline 31112 & Bosque de Mangle & 69,76 & 69,76 & 0 \\
\hline 521 & Lagunas Costeras & $2.420,72$ & $2.383,28$ & $-37,44$ \\
\hline 244 & Mosaico de pastos con espacios naturales & 742,7 & 198,16 & $-544,54$ \\
\hline 421 & Pantanos costeros & 672,95 & 201,61 & $-471,34$ \\
\hline 233 & Pastos Enmalezados o Enrastrojados & 407,87 & 74,05 & $-333,82$ \\
\hline 231 & Pastos Limpios & 44,73 & 120,03 & 75,3 \\
\hline 331 & Playas, Arenales y Dunas & 205,02 & 879,28 & 674,26 \\
\hline 111 & Tejido urbano continuo & 11,54 & 12,25 & 0,71 \\
\hline 323 & Vegetación secundaria o en transición & 941,62 & 492,09 & $-449,53$ \\
\hline 411 & Zonas Pantanosas & 5,56 & 5,56 & 0 \\
\hline & Total general & $7.319,42$ & $7.319,42$ & 0 \\
\hline
\end{tabular}

Tabla 5. Estadísticas de cambio

\begin{tabular}{|l|l|r|r|}
\hline \multicolumn{1}{|c|}{ Cobertura 1987 } & \multicolumn{1}{|c|}{ Pasó a ser en $\mathbf{2 0 0 7}$} & \multicolumn{1}{c|}{ Area (Has) } & \multicolumn{1}{c|}{$\%$} \\
\hline Arbustal Abierto & & $\mathbf{3 0 2 , 9 2}$ & $\mathbf{1 0 0 , 0 0}$ \\
\hline & Arbustal Abierto & $\mathbf{1 3 6 , 9 9}$ & 45,22 \\
\hline & Arbustal Denso & $\mathbf{2 8 , 4 9}$ & 9,41 \\
\hline & Mosaico de pastos con espacios naturales & $\mathbf{2 4 , 2}$ & $\mathbf{7 , 9 9}$ \\
\hline & Playas, Arenales y Dunas & 111,4 & 36,78 \\
\hline & Vegetación secundaria o en transición & 1,82 & 0,60 \\
\hline & & $\mathbf{1 . 4 1 9 , 7 5}$ & $\mathbf{1 0 0 , 0 0}$ \\
\hline & & 314,42 & 22,15 \\
\hline & Arbustal Abierto & 910,82 & 64,15 \\
\hline & Arbustal Denso & 2,34 & 0,16 \\
\hline & Lagunas Costeras & 27,81 & 1,96 \\
\hline & Mosaico de pastos con espacios naturales & 26,13 & 1,84 \\
\hline & Pantanos costeros & 29,73 & 2,09 \\
\hline & Pastos enmalezados o enrastrojados & 42,42 & 2,99 \\
\hline & Pastos Limpios & 0,87 & 0,06 \\
\hline & Tejido urbano continuo & 65,16 & 4,59 \\
\hline
\end{tabular}




\begin{tabular}{|c|c|c|c|}
\hline Cobertura 1987 & Pasó a ser en 2007 & Area (Has) & $\%$ \\
\hline \multirow[t]{2}{*}{ Bosque de galería o ripario } & & 74,28 & 100,00 \\
\hline & Bosque de galería y ripario & 74,28 & 100,00 \\
\hline \multirow[t]{2}{*}{ Bosque de Mangle } & & 69,75 & 100,00 \\
\hline & Bosque de Mangle & 69,75 & 100,00 \\
\hline \multirow[t]{4}{*}{ Lagunas Costeras } & & $2.420,71$ & 100,00 \\
\hline & Lagunas Costeras & $2.380,93$ & 98,36 \\
\hline & Pantanos costeros & 39,76 & 1,64 \\
\hline & Vegetación secundaria o en transición & 0,01 & 0,00 \\
\hline \multirow[t]{10}{*}{$\begin{array}{l}\text { Mosaico de pastos con } \\
\text { espacios naturales }\end{array}$} & & 742,69 & 100,00 \\
\hline & Arbustal Abierto & 227,03 & 30,57 \\
\hline & Arbustal Denso & 288,74 & 38,88 \\
\hline & Mosaico de pastos con espacios naturales & 81,78 & 11,01 \\
\hline & Pantanos costeros & 53,26 & 7,17 \\
\hline & Pastos enmalezados o enrastrojados & 13,18 & 1,78 \\
\hline & Pastos Limpios & 11,42 & 1,54 \\
\hline & Playas, Arenales y Dunas & 33,11 & 4,46 \\
\hline & Tejido urbano continuo & 5,33 & 0,72 \\
\hline & Vegetación secundaria o en transición & 28,8 & 3,88 \\
\hline \multirow[t]{4}{*}{ Pantanos costeros } & & 672,95 & 100,00 \\
\hline & Arbustal Abierto & 64,27 & 9,55 \\
\hline & Pantanos costeros & 79,2 & 11,77 \\
\hline & Playas, Arenales y Dunas & 529,46 & 78,68 \\
\hline \multirow[t]{6}{*}{$\begin{array}{l}\text { Pastos Enmalezados o } \\
\text { Enrastrojados }\end{array}$} & & 407,86 & 100,00 \\
\hline & Arbustal Abierto & 64,55 & 15,83 \\
\hline & Arbustal Denso & 182,84 & 44,83 \\
\hline & Pastos Limpios & 16,92 & 4,15 \\
\hline & Playas, Arenales y Dunas & 0,25 & 0,06 \\
\hline & Vegetación secundaria o en transición & 143,28 & 35,13 \\
\hline \multirow[t]{2}{*}{ Pastos Limpios } & & 44,72 & 100,00 \\
\hline & Pastos Limpios & 44,72 & 100,00 \\
\hline \multirow[t]{2}{*}{ Playas, Arenales y Dunas } & & 205,02 & 100,00 \\
\hline & Playas, Arenales y Dunas & 205,02 & 100,00 \\
\hline \multirow[t]{3}{*}{ Tejido urbano continuo } & & 11,53 & 100,00 \\
\hline & Arbustal Denso & 0,04 & 0,38 \\
\hline & Pastos enmalezados o enrastrojados & 0,92 & 8,02 \\
\hline
\end{tabular}




\begin{tabular}{|l|l|r|r|}
\hline \multicolumn{1}{|c|}{ Cobertura 1987 } & \multicolumn{1}{|c|}{ Pasó a ser en 2007 } & \multicolumn{1}{c|}{ Area (Has) } & \multicolumn{1}{c|}{$\%$} \\
\hline & Pastos Limpios & 4,52 & 39,24 \\
\hline & Tejido urbano continuo & $\mathbf{6 , 0 3}$ & 52,36 \\
\hline $\begin{array}{l}\text { Vegetación secundaria o en } \\
\text { transición }\end{array}$ & & $\mathbf{9 4 1 , 6 1}$ & $\mathbf{1 0 0 , 0 0}$ \\
\hline & Arbustal Abierto & $\mathbf{7 5 , 6 4}$ & 8,03 \\
\hline & Arbustal Denso & 515,17 & 54,71 \\
\hline & Mosaico de pastos con espacios naturales & $\mathbf{6 4 , 3 5}$ & $\mathbf{6 , 8 3}$ \\
\hline & Pantanos costeros & 3,23 & 0,34 \\
\hline & Pastos enmalezados o enrastrojados & 30,19 & 3,21 \\
\hline & Vegetación secundaria o en transición & 253 & 26,87 \\
\hline Zonas Pantanosas & & $\mathbf{5 , 5 6}$ & $\mathbf{1 0 0 , 0 0}$ \\
\hline & Zonas Pantanosas & 5,56 & 100,00 \\
\hline TOTAL GENERAL & & $\mathbf{7 . 3 1 9 , 4 1}$ & \\
\hline
\end{tabular}

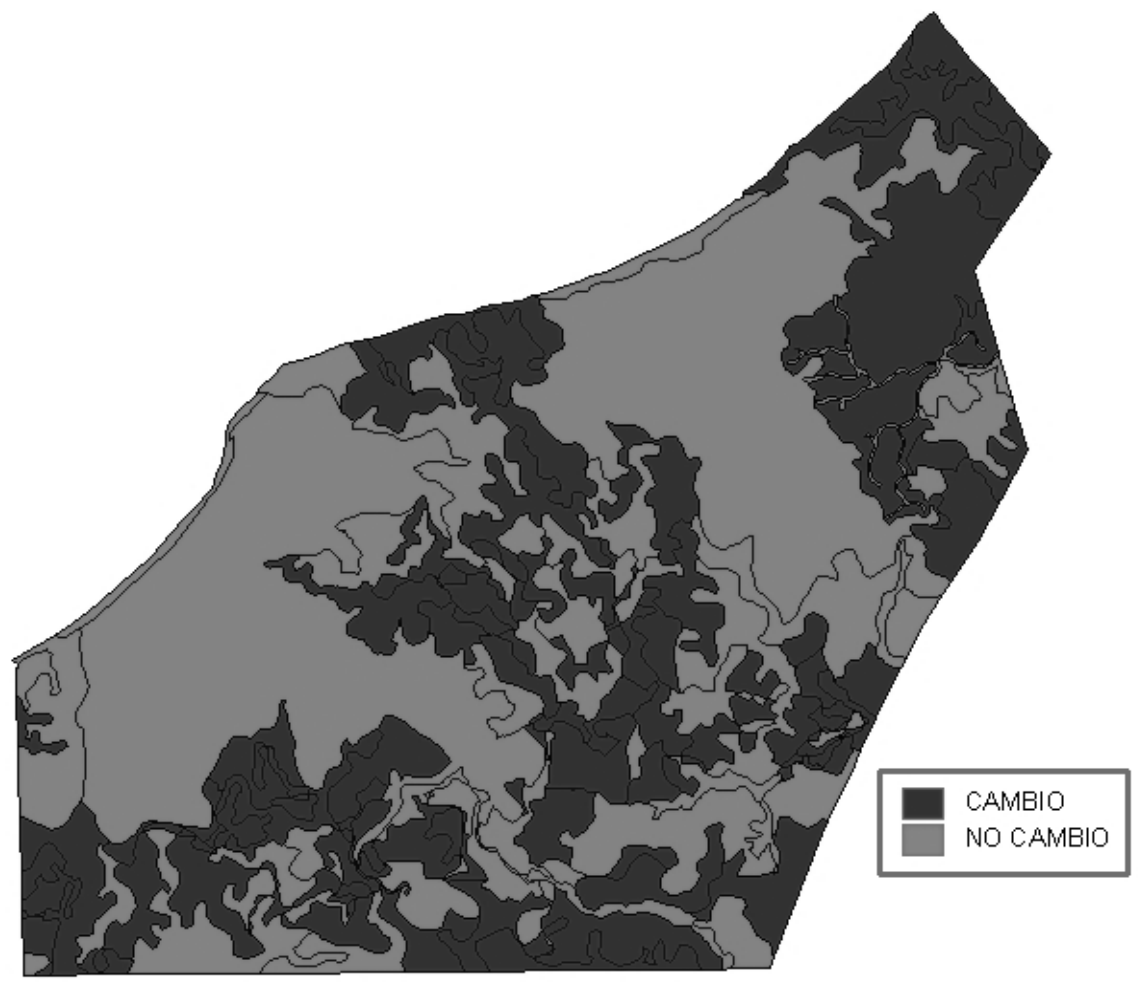

Figura 4. Imagen de cambio de coberturas 
Al final se generó una imagen que muestra el cambio de coberturas (Figura 4 y Tabla 6), para determinar las áreas que más variaron en los años estudiados:

Tabla 6. Porcentajes de cambio

\begin{tabular}{|c|c|c|}
\hline Cambio & Área (has) & $\%$ \\
\hline NO & 4248,14 & 58,03 \\
\hline SI & 3071,27 & 41,97 \\
\hline TOTAL & 7319,42 & 100 \\
\hline
\end{tabular}

\section{CONCLUSIONES}

Entre los años estudiados (1987 y 2007), la cobertura de la tierra ha presentado cambios considerables reportados en un 41\%. Las coberturas que más presentan cambios en este período, son Pastos enmalezados o enrastrojados que se transforman en un 100\% y Mosaico de pastos con espacios naturales que sólo conserva el $11 \%$ del área que cubría en 1987. Estas dos coberturas se transforman principalmente en arbustales densos y abiertos, lo cual puede leerse como un indicador de recuperación de coberturas naturales en el área protegida.

Las coberturas que no presentan cambios son Bosque de galería, Bosque de Mangle, Pastos limpios, Playas arenales y dunas y Zonas pantanosas, lo cual quiere decir que no registraron cambios superiores a 5 hectáreas, dado que ésta es la unidad mínima de reporte de cambio, de acuerdo con la metodología, la escala de trabajo y la resolución de la imagen.

Las coberturas de Lagunas costeras y Pantanos costeros presentan ligeros cambios debido al dinamismo de la marea en estos cuerpos de agua, y a la diferencia en temporalidad de las imágenes insumo, siendo más lluviosa para la imagen de 1987 que para la imagen de 2007. Este puede ser uno de los motivos para observar los cuerpos de agua transformándose en coberturas como Playas arenales y dunas en cierto porcentaje. Sin embargo, cabe resaltar que en términos generales, los cuerpos de agua se han mantenido con el pasar de los 20 años analizados. Esto es de suma importancia para la conservación del hábitat natural de la especie insignia de esta área protegida, los flamencos.

La cobertura denominada Vegetación secundaria o en transición, es por su misma naturaleza, altamente dinámica, lo cual puede comprobarse al observar los porcentajes de cambio que presenta, ya que sólo conserva cerca del $26 \%$ de su cobertura original, mostrando una pérdida de 449 hectáreas. Estos datos demuestran que las coberturas en el santuario al pasar de los años se han vuelto más estables, y conduce a pensar que los niveles de transformación de las mismas son menores y por consiguiente, es menor la intervención antrópica en esta área de conservación. 
Sin embargo, se observa que la cobertura de pastos limpios que es claramente antrópica, mantuvo la ubicación dentro del santuario y se le sumaron 75.3 hectáreas más, ubicadas en los bordes Sur y Oriental del SFF Los Flamencos.

Por último, las coberturas que presentaron un mayor incremento en el área y en la representatividad fueron el Arbustal denso y el Arbustal abierto que representan la cobertura natural más importante del ecosistema del Santuario de Flora y Fauna Los Flamencos, lo cual se puede traducir en una recuperación general de las coberturas del mismo, debido al manejo conservacionista que se le ha dado al área en el período analizado.

\section{REFERENCIAS BIBLIOGRÁFICAS}

[1] Bossard, M., Feranec, J., Otahel., Jaffrain, Gabriel, CORINE Land Cover technical guide Addendum 2000, Technical Report 40, EEA, Copenhagen, 2000. En: http://www.eea.eu.int

[2] Chuvieco, E., El Factor Temporal en Teledetección: Evolución Fenológica y Análisis de cambios. Departamento de Geografía, Universidad de Alcalá.

[3] European Environment Agency. CORINE Land Cover. Commission of the European Communities, 1994.

[4] IDEAM, IGAC, CORMAGDALENA. Metodología CORINE Land Cover Adaptada para Colombia escala 1:100.000, Bogotá, 2008.

[5] Parques Nacionales Naturales de Colombia, SFF LoS Flamencos. En: http://mww.parquesnacionales.gov.co, 2008.

[6] Perdigão, V., y Annoni, A., Technical and methodological guide for updating CORINE Land Cover data base, Joint Research Centre and the EEA, Luxembourg, 1997.

[7] Sesana, L. \& Garcia, A., Colombia: Parques Naturales. Bogotá: Villegas Editores, pp 91-98, 2007. 
